\title{
Simulation of the minimum annual river flows based on the RCP climatic scenario, time horizon up to $2060-2080$ and the Kaczawa River
}

\author{
Leszek Kuchar ${ }^{1, *}$, Slawomir Iwanski ${ }^{1}$, Leszek Jelonek ${ }^{2}$ \\ ${ }^{1}$ Wroclaw University of Environmental and Life Sciences, Department of Mathematics, Grunwaldzka 55, 50357 Wroclaw, Poland \\ ${ }^{2}$ Institute of Meteorology and Water Management, Parkowa 30, 51616 Wroclaw, Poland
}

\begin{abstract}
In this paper a new simulations of minimum daily flow for Kaczawa River a left side tributary of the Odra River in south-west Poland are presented. Generated data were made based on very long series of 35 years of observed data and 24 sites of meteorological stations for south-west Poland gathered from the the Institute of Meteorology and Water Management National Research Institute (IMGW). For the data generation the spatial weather generator SWGEN producing the multisite daily time series was applied. Data were generated for the present (the year 2000 are used as a background) as well for future climate condition for 2060 and 2080 according Representative Concentration Pathways (RCPs) scenarios. The flow simulation in the river catchment is made using MIKE SHE hydrological model. Simulations are done for 2060 and 2080. The large number of new simulated series determined by the lead time, two climate change scenarios (RCP4.5 and RCP6.0), and number of generated years (1000 for each case) is equal to 5000 for a single station. Finally, Lognormal Pdf function for the minimum flow is presented as well probability of exceedance of minimum values.
\end{abstract}

\section{Introduction}

In the following paper the simulation of the minimum river flows based on the RCP climatic scenario, time horizon up to 2060-2080 and the Kaczawa River are presented. In earlier works [1 - 3] simulations for maximum flows and runoff were presented while now the minimum flows were focused on. In the present study, a spatial generator was used as before, but verified on new extended meteorological data $[1,4,5]$.

Until now, the problem of minimal flows or POT flows was of lesser importance in relation to maximum flows, which carry a great risk of floods and losses in the economy. However, in the context of restoring navigability on rivers in Poland, the problem of minimal flows is gaining new and significant significance. Not only the problems of drought and related consequences, but a large plan for the modernization of waterways in Poland, the construction of retention reservoirs and water stages requires new simulations regarding flows on the main rivers in the country. In addition, potential climate changes will have a significant impact on the entire hydrology of river flows and outflows in river basins [3, 6-14]. In the sense that there will be seasonal changes and redistribution of basic components such as rainfall, temperature, evaporation deciding on the water balance $[1,9,12]$. For this reason, actions should be taken today to limit the negative effects of climate change, preceded by comprehensive simulation studies.

The present study uses the procedure used in previous simulations for maximum flows and uses three elements: climate change scenarios, weather generator and hydrological model [1-3, 9, 15-18]. Seasonal flow simulations were performed for a small catchment of the Kaczawa river, the left tributary of the Odra (south-west region of Poland) and selected scenarios of climate change in RCP [1-3, 9].

\section{River flow simulation procedure}

The simulation of minimum river flows for the future climate is carried out in three stages.

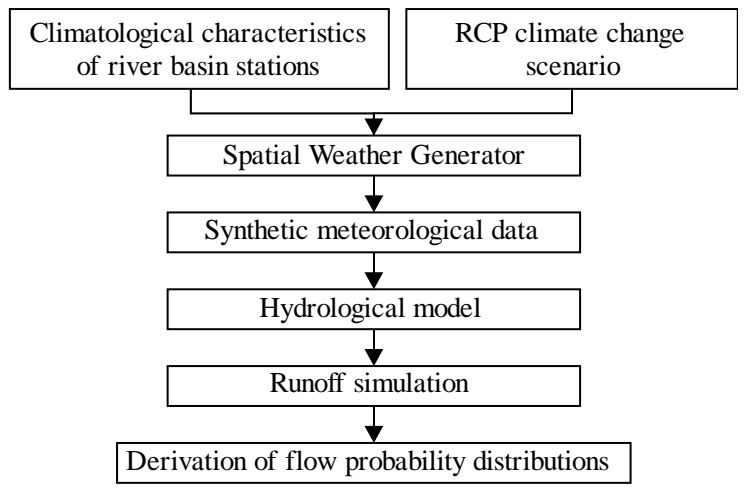

Fig. 1. Diagram of river flow simulation for future climate using synthetic meteorological data and climate change scenario.

First, based on historical data, climate characteristics for all meteorological stations are prepared, which is then modified to include information about potential climate change. The above characteristic is required by 
the generator to generate synthetic data. In the next step, synthetic meteorological data are generated for all stations by the weather generator. These data are used to simulate river flows using the hydrological rainfallrunoff model (step 3). The described procedure is presented in Figure 1 and has been used many times to simulate the maximum flows [1, 2, 3, 4]. Finally, the probability distributions of the minimum flows were adjusted and analyzed based on literature analysis [1-2, 19-25].

\section{Study area and data}

Our research has been conducted for many years in the Kaczawa river basin in south-western Poland (Fig.2) [13, 5]. This choice is related to the Institute of Meteorology and Water Management National Research Institute (IMGW) recommendation and very good meteorological and hydrological data of high quality. A new dataset of the 35-year series of daily observations (1981-2015) for daily solar radiation, maximum and minimum air temperature and total rainfall obtained for 24 stations from the IMGW network was used for this research.

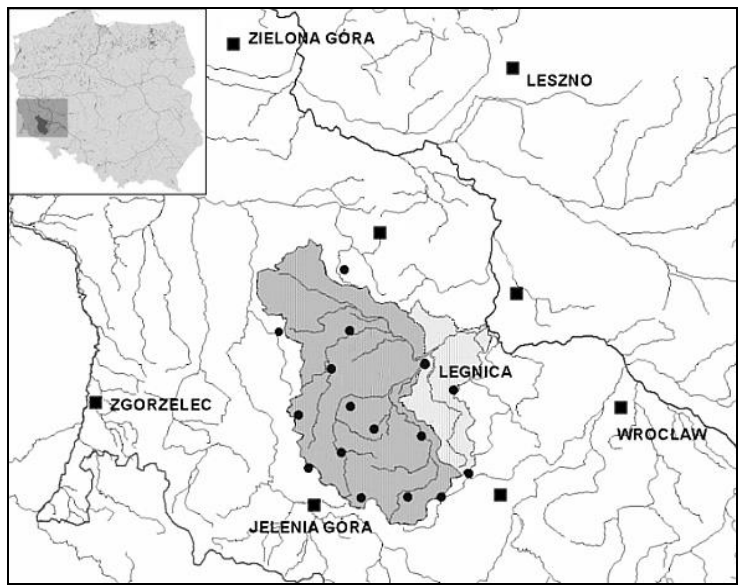

Fig. 2. The Kaczawa River catchment (left, area of $1807 \mathrm{~km} 2$, main sit: Legnica $51^{\circ} 13^{\prime} \mathrm{N}, 16^{\circ} 14^{\prime} \mathrm{E}$ ) with meteorological $(\bullet)$ and first order (घ) meteorological stations.

Another input for flow simulation is an information about climate change. A new set of climate scenarios for the new climate simulations given by Representative Concentration Routes (RCP) was used [2, 9]. New RCP scenarios are introduced for simulations because predictions for surface temperature for Poland are more adequate comparing to previous SRES scenarios. Two typical RCP scenarios (RCP4.5, RCP6.0) were used, which correspond to changes in $\mathrm{CO} 2$ concentrations in Poland, amounting to $538 \mathrm{ppm}$ and $670 \mathrm{ppm}$ respectively up to 2100 . With additional consideration of changes in $\mathrm{CH} 4$ and $\mathrm{N} 2 \mathrm{O}$ emissions, the total concentration would be equivalent to $\mathrm{CO} 2$ values of $630 \mathrm{ppm}$ and $800 \mathrm{ppm}$. For this reason, two RCP4.5 and RCP6.0 scenarios are considered in the simulations, which are similar to the GISS Model E, HadCM3, and GFDL R15 scenarios previously used in Poland [2].

\section{Spatial weather generator and rainfall runoff model}

Modeling of spatial phenomena, especially flows in the rivers described here, requires high quality data simulated by a weather generator [25-32]. A high quality weather generator means that the generated data has the same probability distributions as the observed climatic data.

A spatial weather generator is a development of a point generator, ie for one place and taking into account the correlation between stations and meteorological variables. Is the best downscaling method. According to [1-3] the most well-known applications of spatial data simulated by spatial weather generators are used in hydrology and water management. The spatial data generation by the weather generator is widely described in the literature [1, 3, 16, 25-28, 31]. In a number of applications in Poland, the SWGEN weather generator is used to generate daily data for $\mathrm{n}$ years and for $\mathrm{k}$ stations [1-4].

As described in our earlier papers [1-4] the SWGEN model generates total precipitation by means of the firstorder Markov chain to determine the occurrence of wet/dry days, and then for the amount of precipitation the tuple of correlated two-parameter gamma distributions is used [1-4]:

$$
\left(\Gamma_{m}\left(\alpha_{1}, \beta_{1}\right), \ldots\right.
$$

where $m$ is the month number $(m=1, \ldots, 12$, i.e. January $=1$, Feburary $=2, \ldots$, December $=12)$ and $k$ is the location number. Daily values of solar radiation (SR), temperature maximum $\left(\mathrm{T}_{\max }\right)$ and minimum $\left(\mathrm{T}_{\min }\right)$ are treated as a multidimensional time series $\mathrm{AR}(1)$ in the following form:

$\mathrm{X}_{\mathrm{t}}$

where $\mathbf{X}_{\mathbf{t}}$ and $\mathbf{X}_{\mathbf{t}-\mathbf{1}}$ are vectors $(3 k \times 1)$ of standardized values for all three variables for day $t$ and $t-1, \varepsilon_{\mathbf{t}}$ is a vector $(3 k \times 1)$ of independent random components normally distributed with vector of means equal to zero and matrix of covariance $\boldsymbol{\Sigma}_{\mathbf{m}}$, and $\boldsymbol{\Phi}_{\mathbf{m}}$ (for $m=1, \ldots$, 12) is a matrix of parameters [1-4].

According to the SWGEN model, for each catchment station, statistical characteristics were determined for meteorological variables: solar radiation (SR), minimum and maximum temperature (Tmin and Tmax) and precipitation sum (P) [1-3]. Each meteorological parameter was represented by its monthly mean value and standard deviation. In addition, the correlations among variables from all stations were added to the characteristics. For missing data of solar radiation values were obtained from sky cover measurements (IS) according to the Black formula [1, 2]. Also, for the stations with the lack of measurements of a given meteorological parameter, these characteristics were obtained with the use of interpolation techniques: ordinary kriging and inverse distance weighting method 
$[1,3,24]$. The selection of best interpolation technique was performed with the use of cross-validation test with the root mean square error (RMSE) criteria [24, 33]. Finally, the SWGEN was used to produce long series of 1000 years of synthetic data for 24 stations as an input for the rainfall runoff model.

In the last step, generated data are applied to the MIKE SHE hydrological model $[1,17]$ to simulate daily flows for closing water-gauges. In this study, 2000 was chosen as a reference year to identify potential changes in the minimum river flows. For each simulation, the pdf functions of flows were defined and compared with each other [1-4].

\section{Results}

As in our previous papers [1-3,5] the simulations of daily runoff in the Kaczawa River catchment were done at discharge point in Piątnica. The simulations were done for the time horizon 2060, 2080 with 2000 as a reference year. Two averaged climate change scenarios RCP4.5 and RCP6.0 were considered. The number of generated years (1000) for each case, with total of 5000 $(2 \times 2 \times 1000+1000)$ simulations for the flow. The rainfallrunoff MIKE SHE model was used in each year for the simulation a daily flow and minimum annual flow selection at discharge point (basic information about the minimum annual flows are included in table 1).

Table 1. Means, standard deviations, maximum and minimum of annual minimum flow, different time horizon and scenarios.

\begin{tabular}{|c|c|cccc|}
\hline $\begin{array}{c}\text { Time } \\
\text { horizon }\end{array}$ & Scenario & Mean Std Dev Maximum Minimum \\
\hline 2000 & Present & 1.11 & 0.37 & 2.77 & 0.46 \\
\hline 2060 & RCP4.5 & 1.43 & 0.44 & 2.63 & 0.51 \\
& RCP6.0 & 1.46 & 0.51 & 3.61 & 0.57 \\
\hline 2080 & RCP4.5 & 1.45 & 0.45 & 3.22 & 0.51 \\
& RCP6.0 & 1.36 & 0.43 & 3.46 & 0.58 \\
\hline
\end{tabular}

Table 2. Kolmogorov-Smirnov (K-S) goodness-of-fit test for annual minimum flow, Lilliefors (LF), Shapiro-Wilk

(SW) tests for logarithm of anual minimum flow, different time horizon and scenarios.

\begin{tabular}{|c|c|ccc|}
\hline $\begin{array}{c}\text { Time } \\
\text { horizon }\end{array}$ & Scenario & $\begin{array}{c}\text { K-S } \\
(\mathrm{p}-\mathrm{value})\end{array}$ & $\begin{array}{c}\text { LF } \\
(\mathrm{p}-\mathrm{value})\end{array}$ & $\begin{array}{c}\text { SW } \\
(\mathrm{p}-\mathrm{value})\end{array}$ \\
\hline 2000 & Present & 0.0261 & 0.0261 & 0.9954 \\
& & $(0.9464)$ & $(>0.5)$ & $(0.2527)$ \\
\hline 2060 & RCP4.5 & 0.0318 & 0.0318 & 0.9947 \\
& & $(0.8086)$ & $(0.4260)$ & $(0.1640)$ \\
& RCP6.0 & 0.0403 & 0.0403 & 0.9936 \\
& & $(0.5294)$ & $(0.1211)$ & $(0.0808)$ \\
\hline 2080 & RCP4.5 & 0.0429 & 0.0430 & 0.9907 \\
& & $(0.4458)$ & $(0.0744)$ & $(0.0145)$ \\
& RCP6.0 & 0.0301 & 0.0301 & 0.9968 \\
& & $(0.8575)$ & $(>0.5)$ & $(0.5503)$ \\
\hline
\end{tabular}

For daily annual minimum flow values two parameters Lognormal (LN2) density function was applied, and for maximum likelihood parameter estimation 1000 observations were used. It means that the probability distribution parameters were estimated for five combinations $(2 \times 2+1)$, using 1000 year series each. Results of goodness-of-fit tests are in Table 1 . No test rejects the hypothesis of Lognormal distribution at the $1 \%$ significance level. Probability density functions (PDF) of annual minimum flow for the Kaczawa River for two RCPs scenarios and two time horizon (2060, 2080) and present conditions (year 2000) are shown on the Figure 3.
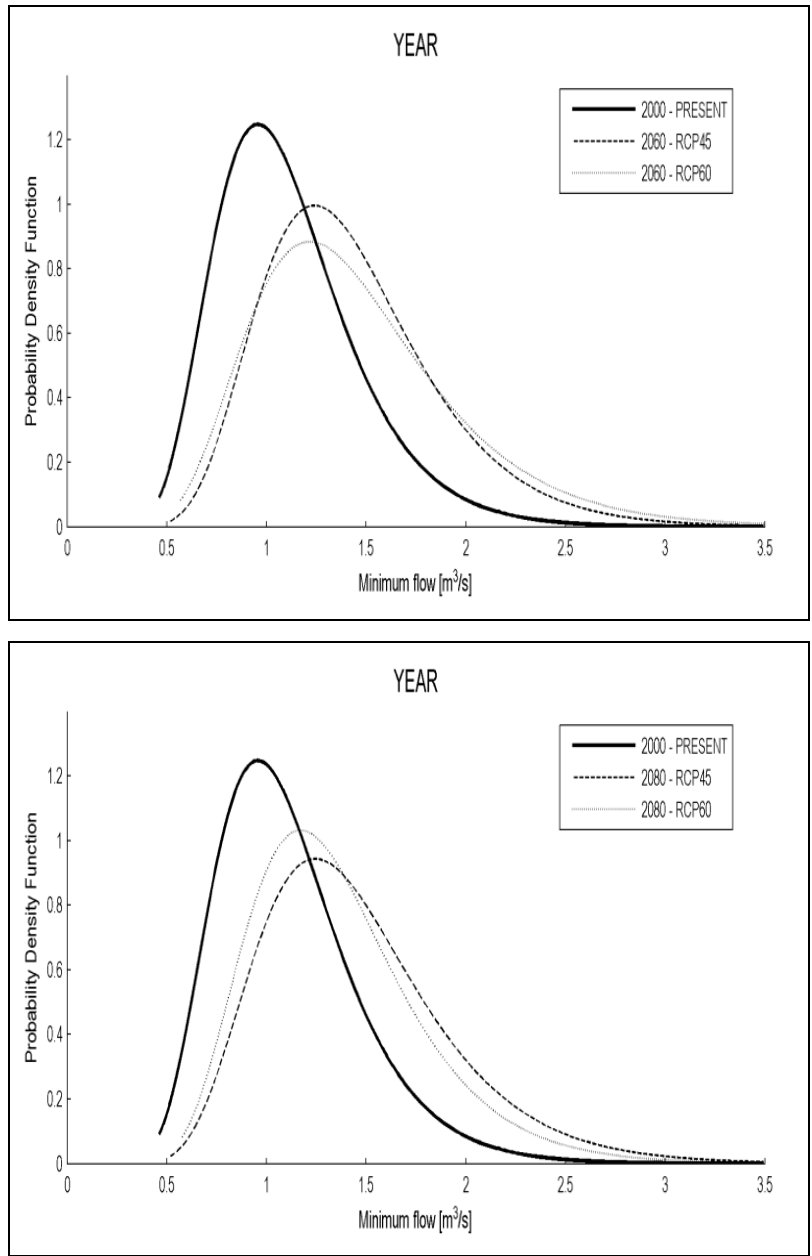

Fig. 3. Pdf function of annual mimimum flow at discharge point in Piątnica on the Kaczawa River, simulation for present conditions (year 2000) and RCPs scenarios for 2060 (upper graph) and 2080 (lower graph).

Analysis of probability distributions (Tab.2, Fig. 3) indicates changes in the annual minimum flows in the time horizon up to 2080. In relation to the reference year (2000), the minimum annual flow is increased about 20 $30 \%$. The variance of the minimum flow also increases (about $40 \%$ ). A larger increase in the minimum flow is simulated for the RCP 6.0 and 2060 scenario, while smaller for the year 2080. Changes in the minimum annual flows simulated for RCP scenarios correspond to the results obtained for the simulations using scenarios of SRES A1B [1-3]. The increase in the minimum annual flow with a moderate increase in variance can be seen positively, due to Poland's water resources.

Figure 4 shows probability of exceedance of minimum annual flow at discharge point at Piątnica for 
present conditions (year 2000) and two RCPs scenarios for 2060 and 2080.

Analysis of probabilities of exceeding the minimum flow indicates a good fitting of the Lognormal distribution to the minimum annual flows for most values of the random variable. A worse fitting is only observed for larger low flow values, i.e. for the right tail of the probability distribution.
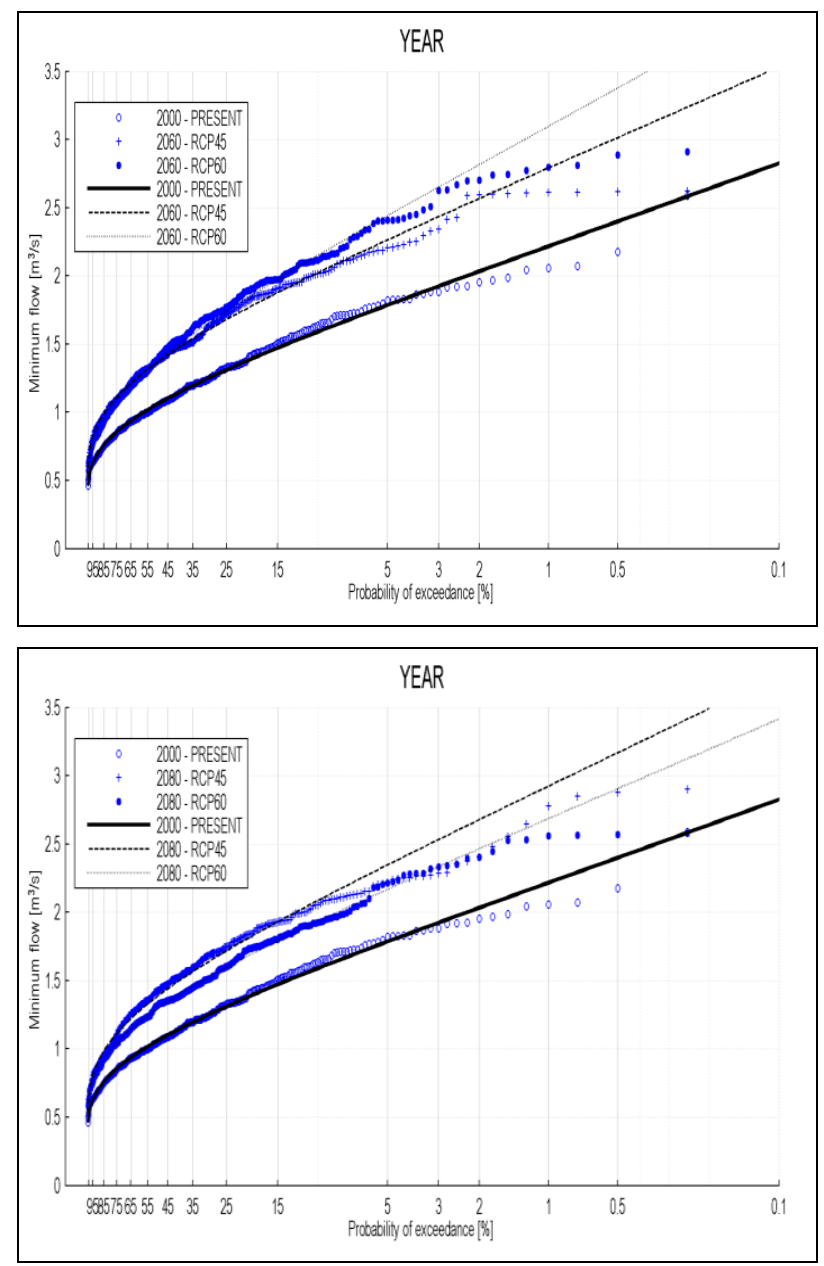

Fig. 4. Probability of exceedance of minimum flow within the year (October - September) at discharge point at Piątnica on the Kaczawa River, simulation for present conditions (year 2000) and RCPs scenarios for 2060 (upper graph) and 2080 (lower graph).

The above simulations also leads to the more general remarks. The impact of climate change on outflows and changes in flows can be effectively simulated using a spatial weather generator SWGEN in combination with a hydrological outflow and fall model (MIKE SHE Ed. 2008) [20, 21, 23]. According to climate change scenarios, simulations of flows in the river basin can be made with a time horizon of up to 60-80 years.

Application of Lognormal probability distribution for the minimum annual river flow gives detailed information on the moment characteristics, confidence intervals and critical values. The simulations of the minimum daily flows within the year in the Kaczawa River basin indicate changes in flows depending on the scenario of climate change and the horizon of the forecast.
New simulations with RCPs scenarios give similar results as previously used SRES A1B scenarios (GISS Model E, HadCM3 and GFDL R15) [17]. Application of Lognormal probability distribution shows some uncertainties for tail fitting, and suggests future studies, particularly nonparametric estimation. However, simulations show some changes of exceedance of minimum annual flow, RCPs scenarios and eighty-year lead time.

\section{Conclusion}

The use of the SWGEN spatial weather data generator together with the hydrological rainfall-runoff model MIKE SHE enables effective assessment of changes in flows in river basins with a long time horizon.

The simulated minimum annual flows predicted for 2060 and 2080 according to the averaged scenarios RCP4.5 and RCP6.0 are consistent with the minimum annual flows obtained for the SRES A1B scenarios (GISS Model E, HadCM3 and GFDL R15) in earlier studies.

A 20 percent increase in the minimum annual daily flows in the case of significant water deficits in Poland is not a hydrological risk to the catchment of the Piątnica River.

The long series of simulated years and the large number of stations used in calculations based on 35 years of observation allow us to believe that the simulations in flow changes in Kaczawa basin are reliable.

\section{References}

1. L. Kuchar, S. Iwanski, L. Jelonek, W. Szalinska, Geografie 119, 1 (2014)

2. L. Kuchar, S. Iwanski, L. Jelonek, E3S Web of Conf. 17, 00046 (2017) doi: 10.1051/e3sconf/20171700046

3. L. Kuchar, S. Iwanski, L. Jelonek, W. Szalinska, Meteorol. Hydrol. Water Manage. 2, 2, 49 (2014)

4. S. Iwanski, L. Kuchar, Acta Scientiarum Polonorum - Formatio Circumiectus 2, 113 (2003)

5. L. Kuchar, S. Iwanski, E3S Web of Conf. 44, 00083 (2018) doi: 10.1051/e3sconf/20184400083

6. G.A. Baigorria, J.W. Jones, J. Clim. 23, 22, 5990 (2010)

7. S. Bergström, B. Carlsson, M. Gardelin, G. Lindström, A. Pettersson, M. Rummukainen, Clim. Res. 16, 101 (2001)

8. H. Chen, C.Y. Xu, S. Guo, J. Hydrol. 434-435, 36 (2012)

9. IPCC WG I, II and III, Climate Change, Synthesis Report (IPCC, Geneva, 2014)

10. T. Barnett, T. Malone, W. Pennell, D. Stammer, B. Semtner, W. Washington, Clim. Change 62, 1 (2004)

11. N.S. Christensen, A.W. Wood, N. Voisin, D.P. Lettenmaier, R.N. Palmer, Clim. Change 62, 337 (2004) 
12. S. Bac, S. Iwanski, L. Kuchar, Acta Agrophysica 12, 2, 305 (2008)

13. D.I. Müller-Wohlfeil, G. Bürger, W. Lahmer, Clim. Change 47, 61 (2000)

14. Z. Szwejkowski, E. Draganska, I. Cymes, C.M. Timofte, S. Suchecki, I. Craciun, Meteorol. Hydrol. Water Manage. 5, 1, 15 (2017)

15. F. Brissette, M. Khalili, R. Leconte, J. Hydrol. 345, 121 (2007)

16. J. Chen, F.P. Brissette, X.C. Zhang, Trans. ASABE 57, 1375 (2014)

17. M.B. Abbott, J.C. Bathurst, J.A. Cunge, P.E. O'Connell, J. Rasmussen, J. Hydrol. 87, 61 (1986)

18. D.N. Graham, M.B. Butts, Watershed Models V.P. Singh, D.K. Frevert (Eds.), (CRC Press, Boca Raton, 2006)

19. D.N. Graham, M.B. Butts, Watershed Models V.P. Singh, D.K. Frevert (Eds.), (CRC Press, Boca Raton, 2006)

20. M. Wdowikowski, B. Kazmierczak, O. Ledvinka, Meteorol. Hydrol. Water Manage. 4, 1, 53 (2016)

21. L. Kuzminski, L. Szalata, J. Zwozdziak, Pol. J. Environ. Stud. 27, 4, 1583 (2018)

22. A. Michalski, Meteorol. Hydrol. Water Manage. 4, 1, 41 (2016)
23. T. Tokarczyk, W. Szalinska, A. Tiukalo, J. Jelowicki, A. Chorazyczewski, Meteorol. Hydrol. Water Manage. 4, 1, 65 (2016)

24. R.E. Walpole, R.H. Myers, S.L. Myers, K. Ye, Probability and statistics for engineers and scientists (Prentice Hall, NJ, 2002)

25. D.I. Jeong, A. St-Hilaire, T.B.M.J. Ouarda, P. Gachon, Clim. Res. 54, 2, 129 (2012)

26. R. Srikanthan, G.G.S. Pegram, J. Hydrol. 371, 142 (2009)

27. C.G. Kilsby, P.D. Jones, A. Burton, A.C. Ford, H.J. Fowler, P. James, A. Smith, R.L. Wilby, Environ. Mod. Soft. 22, 12, 1705 (2007)

28. Y. Xu, Ch. Ma, S. Pan, Q. Zhu, Q. Ran, J. Zhejiang Univ. Sci. A 15, 3, 219 (2014)

29. L. Kuchar, Int. Agrophys. 8, 3, 525 (1995)

30. S.E. Hollinger, L. Kuchar, Math. Comp. Symul. 42, 2-3, 293 (1996)

31. M. Khalili, F. Brissette, R. Leconte, J. Am. Wat. Res. Ass. 47, 2, 303 (2011)

32. W. Szulczewski, W. Jakubowski, Water Resour. Manage., accepted on April, 302018 (2018) https://doi.org/10.1007/s11269-018-2005-6

33. L. Kuchar, Math. Comp. Symul. 65, 1-2, 69 (2004) 